\title{
Role of Human Resource Information Systems in an Educational Organization
}

\author{
Ritesh Chugh \\ School of Engineering and Technology, Central Queensland University Melbourne, Australia \\ Email: r.chugh@cqu.edu.au
}

\begin{abstract}
It is vital that the human resource function in organisations is supported by information systems to be able to deliver services and improve operations. Human Resource Information Systems (HRIS) provide a means of acquiring, storing, analysing and distributing information to various stakeholders. HRIS enable improvement in traditional processes and enhance strategic decision making. This paper bases its discussion on the role of HRIS in the human resource function. The paper explores the usage of HRIS in an educational organisation. Process descriptions in the human resource function indicate how HRIS supports the organisation's processes with relevant anecdotes under each key process. The findings of the paper will encourage other similar organisations to adopt HRIS as its usage becomes more widespread.
\end{abstract}

Index Terms-human resources, human resource information systems, human resource management

\section{INTRODUCTION}

Human Resource (HR) management is recognised as being critical for the success of organisations globally. The role of HR function is considered to be a supportive role since no other business functions or processes can be fulfilled without initial input from HR. HR function can be defined as an organisational function or unit that deals with people in employing, training, promoting, terminating, record keeping and meeting other legal requirements [1]. HR function also contributes towards an organisation's strategic planning and its development. HR function becomes competent by efficiently obtaining, developing and preserving its resources that are crucial for an organisation to gain advantage over its competitors and for smooth operation of the entire organisation. Apart from the traditional process of hiring employees, one of the major tasks for $\mathrm{HR}$ is to acquire and maintain complex volumes of information that can be further classified, cross checked and retained for future use which is a complex task in itself.

Adoption of information systems by organisations has gained momentum in recent years. Expectations of customers and organisations on HR professionals has increased over the years and the accelerated pace of technology has encompassed procedures and possibilities that were not possible in previous years. The availability of computerised systems has made acquiring, storing and using information possible and efficient. Apart from obtaining and maintaining data, advancements in technology have enabled analysis and manipulation of the data. Evolution of information systems has led to its rapid use by HR to improve processes thus facilitating improved performance. A study by Hussain, Wallace and Cornelius [2] has shown that the use of information systems improves the efficiency of $\mathrm{HR}$ roles and contributes towards achieving an organisation's strategic development. As organisations become more complex and their information management needs increase, the need for relevant information systems also increases dramatically.

This paper lays particular emphasis on Human Resource Information Systems (HRIS) and the role information systems play in assisting HR professionals in performing functional business processes. Information systems can be defined as 'a set of interrelated components that collect, process, store, and distribute information to support decision making and control in an organisation' [3] whereas HRIS can be defined as 'computer based technique of collecting, storing, maintaining data and retrieving information about employees and their jobs' [4]. The similarity in both definitions is obvious with the prime difference being the use of information systems to assist HR activities. Repetitive manual tasks and information storage are now being computerised making any workforce more productive with HR function being no exception. Introduction of HRIS has helped HR personnel to concentrate less on repetitive administrative tasks and concentrate more on organisational strategic goals. HRIS help to analyse and process data that is further used as a supporting tool for decision making. Various tools can be an integral part of HRIS but for the purposes of this paper the discussion focuses on a generic HRIS.

This paper is organised as follows. The next section provides an insight into HRIS and its benefits. Section III outlines the research methodology. In Section IV, the paper focuses its attention towards a chosen organisation to analyse the use of HRIS and its usefulness in performing core HR functional processes and its role in supporting an organisation's strategic direction. Finally, the key premises of the paper have been summarised and the paper's limitations are explicitly stated with an outlook for possible future research. 
In recent years there has been a rapid change in the way HR function is perceived in organisations compared to the conventional HR function that existed a few years ago. Various studies conducted over recent years have suggested that use of information systems by the HR function has improved the functionality and performance of the function and organisation as a whole [5]-[7] although research in Australia and the United Kingdom has revealed that HRIS are being underutilised [8]. Organisations that use HRIS have been shown to gain competitive advantage over the companies that do not use HRIS [9]. HRIS can reduce the duplication of day to day administrative tasks by streamlining various processes and producing quality and integrated information [6]. Storage and retrieval of large volume of information is now easy with usage of HRIS [5]. While the initial cost of installing and updating HRIS is expensive, depending on the nature of organisational goals, requirements and priorities, simple HRIS or customised HRIS can be adopted [10]. Eventually the advantages of HRIS will outweigh the costs, if the system is used optimally.

While information systems were used for standardisation of information, lately there have been developments in HRIS contributing towards saving on administrative costs and leading to many new applications making HR tasks less autonomous and empowering the whole HR function [11]. Miner and Crane [12] suggest that HRIS are designed as planning systems that can manipulate information to exemplify accurate and timely data that is vital in decision making during change. Some of the main benefits of having HRIS in an organisation have been identified in Table I [13]-[15].

\section{TABLE I. BENEFITS OF HRIS}

\begin{tabular}{|ll|}
\hline$\bullet$ & $\begin{array}{l}\text { Reduced workload by minimizing repetitive } \\
\text { administrative tasks like acquiring, storing, upgrading and } \\
\text { manipulation of large volumes of information. }\end{array}$ \\
\hline$\bullet$ & $\begin{array}{l}\text { Improved analysis of the available information to support } \\
\text { in decision making. }\end{array}$ \\
\hline$\bullet$ & Reduced manpower costs. \\
\hline$\bullet$ & Timely response to queries. \\
\hline$\bullet$ & Greater information accuracy. \\
\hline$\bullet$ & Produce a variety of HR-related reports \\
\hline
\end{tabular}

\section{METHODOLOGY}

The paper now explores CLearn, an educational organisation, to identify the usage of HRIS. The name of the organisation that has been analysed has been withheld for confidentiality reasons and the pseudonym CLearn organisation has been used instead. CLearn is an organisation that delivers and distributes educational services to international students which attributes its success for its focus on people, service and quality. CLearn employs around 250 full time employees and around 400 casual employees. Cost reduction and flattening of hierarchy is a strategic goal for CLearn.

An exploratory case study method helps to investigate a 'contemporary phenomenon in depth and within its real-life context, especially when the boundaries between phenomenon and context are not clearly evident' [16] and in which multiple sources of evidence are used. Therefore case study research method is chosen as it provides clarity and in-depth understanding of complex matters and adds strength to what is already established through previous studies.

\section{HRIS IN THE ORGANISATION}

The HR information system used in CLearn is chris ${ }^{21}$ (Complete Human Resource Information System). chris ${ }^{21}$ is an integrated HR software solution produced by Frontier Software Pty Ltd. It provides integrated human resources and payroll management modules by connecting an Internet based network to a central application server running the back end processes [17]. Chris $^{21}$ offers a range of HR process modules like recruitment, payroll, occupational health and safety, report designing and managing learning and development and so forth. CLearn organisation uses it for organisation and position management, staff information, and HR functional management. Fig. 1 outlines the key processes for which chris ${ }^{21}$ is used at CLearn. Process descriptions after the figure indicate how HRIS supports the organisation's strategic direction with relevant anecdotes under each process.

The organisation and position management module in chris $^{21}$ provides an insight to the organisation's management on ways to improve service and productivity, define proper position configuration, develop career ranking and provide strategic direction and guidance on overall organisational structure. One of the major requirements of $\mathrm{HR}$ is to develop and maintain an organisation structure that promotes effective accomplishment of organisational objectives. All key information from identifying a new position to the employment of a suitable candidate is entered and stored in chris ${ }^{21}$ which builds relationship work flow charts and helps in generating organisational charts too.

As there is a lot of data involved in HR management, a reporting engine that can turn simple data into customised data for report generation is very critical for an organisation to take better decisions and optimise business processes. Chris ${ }^{21}$, s web based reporting allows filters which helps in generating customised reports for appropriate decision making at CLearn. In chris ${ }^{21}$, HR reporting module also acts as an open avenue of communication as it provides employees the opportunities to report or log their requirements via phone, email or fax which are logged into the chris ${ }^{21}$ database.

A typical and most common function of HR is to store staff information. Details like name, date of birth, gender, address, staff number, position title, position location, salary, reporting lines and other company specific information is all stored in chris ${ }^{21}$ at the commencement of an employee's tenure. All of the above information was manually entered and stored on paper before migrating to chris ${ }^{21}$. The information is now maintained in chris ${ }^{21}$, s database and is better organised and easily accessible to relevant staff. 


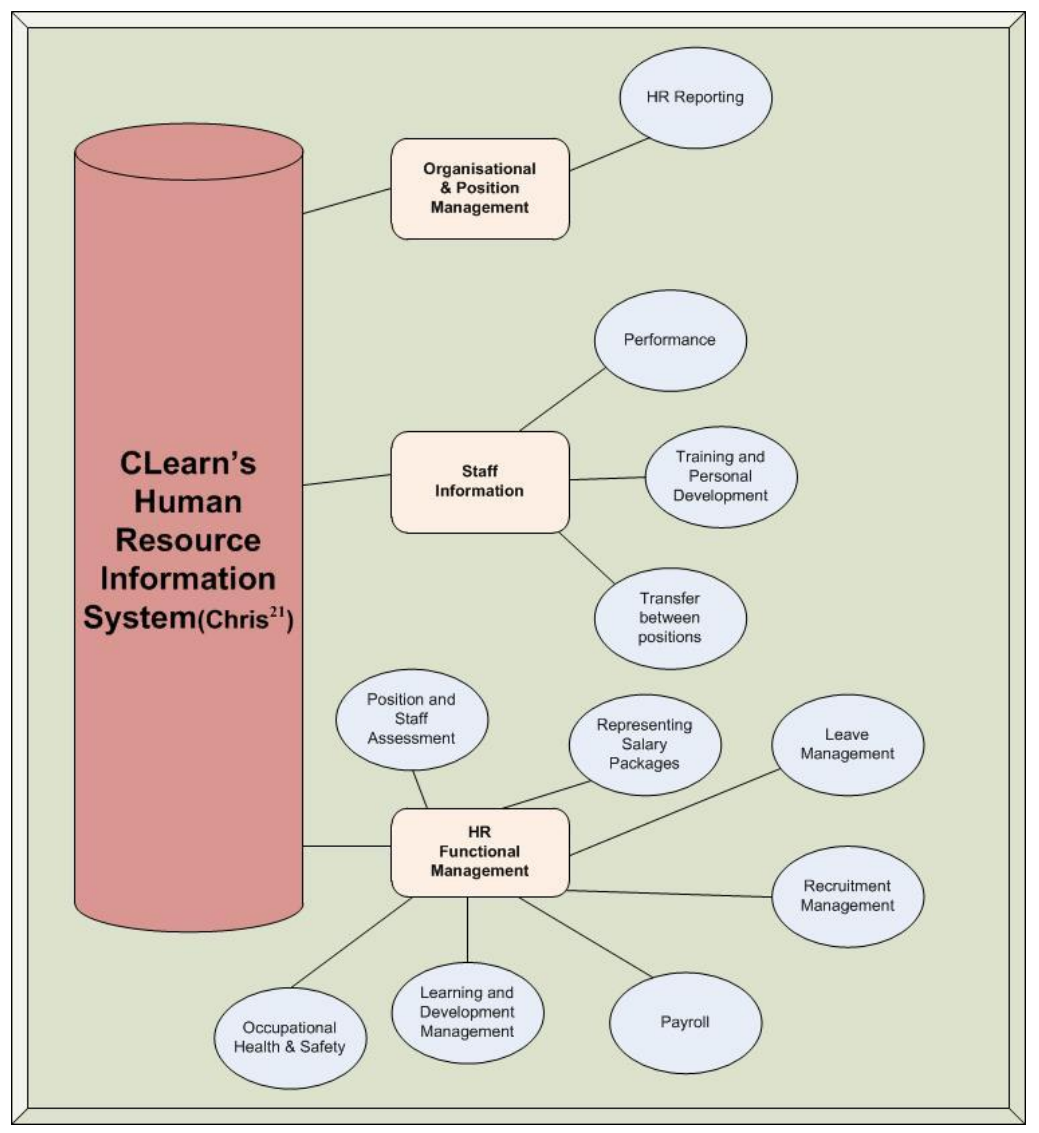

Figure 1. Key processes of HRIS.

The outcomes of the performance review and staff aspirations are stored in chris ${ }^{21}$. Based on every employee's aspirations and depending on the need of the organisation's requirements, staff are categorised and promoted accordingly when the need arises. Staff are nominated for training or professional development and the details of their interests to enhance their professional capabilities are also stored in chris ${ }^{21}$. If a need for a new position arises, the details for the suitable candidate can be screened through chris ${ }^{21}$ which provides organised information about the staff member thereby minimising the process of $\mathrm{HR}$ administrative repetitive task of screening every employee. When there is a requirement for a new role, the system is screened for an ideal candidate with appropriate qualifications. CLearn organisation also allows the candidates to undertake online training by posting information related to the course on the staff intranet. Employees can undergo this training any time as it is available 24/7. This is cost effective to the company as there are no travel expenses and it is a convenient method of learning for employees as they can do the training at their own pace and time.

More than 70 percent of larger organisations have implemented some form of employee self-service HR system [18]. The use of chris ${ }^{21}$ in CLearn has been extended to allow employees to directly enter some personal data into the system over the Internet thus also classifying as a limited self-service system. This reduces the amount of time and paperwork that was previously involved in a simple process like leave approval and management. Chris ${ }^{21}$ also stores information about staff leave. Staff can apply for leave using chris ${ }^{21}$ and check their leave balances. The work flow relationships that are built using the organisation and position management module come in handy in CLearn as every employee is recognised by a staff number and their position is directly linked to the reporting manager. So when an employee applies for leave, an application for leave in chris ${ }^{21}$ is automatically generated and the employee gets a copy and another copy is forwarded to the direct manager of the employee for approval. Emails are sent at every level confirming the application has been lodged and when the outcome is decided, which helps every employee to keep direct track of their leave status. Leave balances are also displayed in chris ${ }^{21}$ for employees' referral.

Use of automated payroll systems has been shown to improve productivity by cutting the costs of printing expenditures [19]. Staff at CLearn receive electronic payslips instead of traditional paper slips. Earlier payroll required several employees to do the manual tasks of ledgering; automation of payroll has helped in cost cutting by minimising manual processes. As the process is now electronic, data relating to transactions can be maintained for as long as required by the organisation thus eliminating storage issues.

An organisation's performance is partly dependent on its employees' effective and efficient management. In workforce planning, it is vital that learning and development of all employees is managed in a systematic approach. CLearn also utilises a chris ${ }^{21}$ learning and 
development management module that includes a wide range of activities that are designed to improve the competence of the employees. Skills enhancing professional development such as mentoring, forums, seminars and skills enhancing technical and communication knowledge like situational and work related training are some of the learning and development activities offered by CLearn to help employees enhance their technical and professional skills. This association allows the system to collate and monitor information for report generation as well as data analysis for decision making and future planning.

Occupational health and safety $(\mathrm{OH} \& \mathrm{~S})$ is monitored through a web based reporting system where all complaints are logged online. Employees and their respective managers have access to this database where they can keep track of any injuries and incidents. The key features of occupational health and safety system in CLearn is to identify any potential hazards and accidents, recognise risks and alleviation tactics, analyse risk and build workflow systems to report and notify the organisation about any potential incidents and store documentary evidence. Using information systems in managing this aspect of human resources has several advantages such as timely response to reported incidents, increased workplace productivity and less time spent on manual administrative tasks of filling forms related to complaints, compensation and reimbursements.

Proficiency of the employees is the greatest asset for any organisation. To increase their efficiency, every organisation needs to develop a system that identifies training necessities of every position and its employees. Chris $^{21}$ helps CLearn identify individual skills, manage staff performance, recognise any gaps for training and provide a workflow that is constructed within required timelines. The access to such information is available to the functional manager to manage employee career paths and employees to keep track of their objectives.

As observed through this discussion, HRIS play an important part in CLearn organisation. HRIS will continue to play an important role in every organisation and serve the needs of strategic, tactical and operational levels of an organisational hierarchy. It is important that every organisation in the future focusses on harnessing the potential of HRIS.

\section{CONCLUSION}

As demonstrated by the various examples of processes in CLearn, the use of HRIS is changing traditional HRM functions and making manual processes automated and efficient. The use of HRIS has led to a total overhaul of the traditional HR management practices in the organisation. As highlighted before, cost reduction and flattening of hierarchy is a strategic goal for CLearn and its achievement would not have been possible without HRIS. HRIS was utilised not only to automate the manual processes but to gain strategic advantages for the organisation. Analysis of the existing practices at CLearn has revealed that there is a strong link in the usage of HRIS. Far from being an isolated example of HRIS usage, this paper illustrates the norm in today's agile work environment.

In conclusion, adequate HRIS are necessary to support an organisation's objective of securing competitive advantage and thus cannot be overlooked regardless of the constraints or resources consumed. A limitation of this paper was that data analysis was only qualitative in nature whereas quantitative data would have been helpful to ascertain the impact CLearn's HRIS is having on their initial investment and the perceptions of staff would have helped strengthen this paper. This limitation calls for further research in the area so that the gaps can be filled. It is also not advisable to assume that the paper revealed the view of CLearn solely but an explorative view presented by the author strengthened with the extant literature. The use of HRIS explored in this paper was limited to CLearn, an educational organisation, but its usage is not restricted to educational organisations alone and similar outcomes can be gained by all organisations.

It can be noticed globally that all organisations now operate in turbulent environments where changes are quick and unpredictable so $\mathrm{HR}$ has a much shorter timescale to respond. CLearn has been very successful in its overall HR management and continues to make changes to improve further. In order to remain competitive and flexible HRIS are on hand to the rescue, if employed timely, but HR function without people is difficult to fathom. Thus, the nature of HR is to be able to constantly juggle people and technology to continue its supportive role and take an organisation into the future. So, information systems can be expected to drive the HR function towards a more strategic role and bring about successful human-technology oriented processes that will make any organisation contemporary.

\section{REFERENCES}

[1] W. P. Anthony, P. L. Perrewe, and K. M. Kacmar, Human Resource Management: A Strategic Approach, Orlando: Dryden, 1999, ch. 1, pp. 5-20.

[2] Z. Hussain, J. Wallace, and N. E. Cornelius, "The use and impact of human resource information systems on human resource management professionals," Information \& Management, vol. 44, no. 1, pp. 74-89, January 2007.

[3] K. C. Laudon and J. P. Laudon, Management Information Systems Managing the Digital Firm, (11th Global edn.), Upper Saddle River: Pearson Education, 2009, ch. 1, pp. 44-47.

[4] A. S. Targowski and S. P. Deshpande, "The Utility and Selection of an HRIS," Advances in Competitiveness Research, vol. 9, no. 1, pp. 42-56, January 2001.

[5] E. W. T. Ngai and F. K. T. Wat, "Human resource information systems: A review and empirical analysis," Personnel Review, vol. 35, no. 3, pp. 297-314, July 2006.

[6] M. Mohanty and S. Tripathy, "HRIS in the Indian Scenario: A case study of a large organization," South Asian Journal of Management, vol. 16, no. 2, pp. 127-168, April-June 2009.

[7] M. R. Olivas-Lujan, J. Ramirez, and L. Zapata-Cantu, "e-HRM in mexico: Adapting innovations for global competitiveness," International Journal of Manpower, vol. 28, no. 5, pp. 418-434, 2007.

[8] J. Macy, "Room to grow," HR Monthly, pp. 42-43, 2006.

[9] M. J. Kavanagh and M. Thite, Human Resource Information Systems - Basics, Applications, and Future Directions, California: Sage Publications, 2009, ch. 1, pp. 6-30.

[10] R. Sobkowiak and R. LeBleu, "Repositioning HR information systems," Information Systems Management, vol. 13, no. 1, pp. 62-64, Winter 1996. 
[11] C. Alleyne, A. Kakabadse, and N. Kakabadse, "Using the HR Intranet: An exploratory analysis of its impact on managerial satisfaction with the HR function," Personnel Review, vol. 36, no. 2, pp. 295-310, August 2007.

[12] J. Miner and D. Crane, Human Resource Management - The Strategic Perspective, Harper Collins College Publishers, 1995, ch. 5, pp. 175-185.

[13] K. Kovach, A. Hughes, P. Fagan, and P. Maggitti, "Administrative and strategic advantages of HRIS," Employment Relations Today, vol. 29, no. 2, pp. 43-48, Summer 2002.

[14] A. Hendrickson, "Human resource information systems: Backbone technology of contemporary human resources," Journal of Labor Research, vol. 24, no. 3, pp. 381-394, September 2003.

[15] E. Beulen, "The Contribution of a global service provider's human resources information system (HRIS) to staff retention in emerging markets: Comparing issues and implications in six developing countries," Information Technology \& People, vol. 22, no. 3, pp. 270-288, April 2009.

[16] R. K. Yin, Case Study Research: Design and Methods, California, Sage Publications, 2009, ch. 1, pp. 18-20.

[17] Frontier Software. Comprehensive Human Resource Integrated Solution. http://www.frontiersoftware.com/products/chris21-integratedhuman-resource-management-payroll

[18] CedarCrestone, Human Resources Self Service/Portal survey, $5^{\text {th }}$ Annual edn, Baltimore; Cedar Group, 2002.

[19] D. Ulrich, "From e-Business to e-HR," Human Resource Planning, vol. 23, no. 2, pp. 12-21, April 2000.

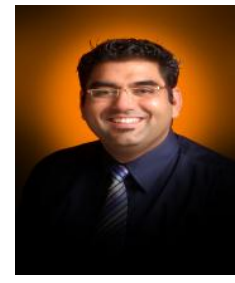

Ritesh Chugh lectures in the School of Engineering and Technology at Central Queensland University Melbourne, Australia. He teaches to both postgraduate and undergraduate students in the fields of Information Systems (IS) Management, Analysis and Development, IS Project Management, and Electronic Commerce. Ritesh has been awarded many teaching awards, over the past few years, recognising his teaching excellence and commitment to improved student outcomes.

His range of interests includes project management, knowledge management, electronic commerce and developing varied teaching and learning practices on a formal note and philately and numismatics on a more casual note.

Ritesh is a member of the Australian Computer Society, senior member of IEEE and IEEE's Computer Society too. 